\title{
Espacio, acción colectiva e identidad: la Vocacional 7 del Instituto Politécnico Nacional durante el movimiento estudiantil de 1968
}




\section{Resumen}

El movimiento estudiantil de 1968 fue producto de una red de alianzas sociopolíticas entre estudiantes de universidades públicas y privadas en México. En este artículo se analizará, desde la sociología de los movimientos sociales y la geografía política y la cultural, cómo se construyó la movilización colectiva en la Vocacional 7, del Instituto Politécnico Nacional; de qué forma se cristalizó el vínculo entre acción colectiva, identidad y espacio; las formas de apropiación material, política y simbólica del mismo, así como qué representa esta escuela para algunos de sus exestudiantes. Para ello, fueron aplicadas dieciocho entrevistas a profundidad a exalumnos de la Vocacional, participantes en este actor colectivo. Como se verá, el espacio fue un recurso de movilización importante, amén de ser un factor que formaba parte de la identidad colectiva.

Palabras clave: Movimiento estudiantil de 1968, identidad colectiva, espacio.

\section{Abstract}

The 1968 student movement was the product of a network of sociopolitical alliances between students from public and private universities in Mexico. In this article I will analyze, from the sociology of social movements and political and cultural geography perspectives, how this collective movement was built in the Vocacional 7, of the National Polytechnic Institute; how the link between collective action, identity and space crystallized; the forms of material, political and symbolic appropriation of the space, as well as what this school represented for some of its former students. For this, eighteen in-depth interviews were applied to alumni of the Vocacional, all of them participants in this social movement. As we will see, space was an important mobilization resource, as well as being a factor that was part of the collective identity.

Keywords: 1968 student movement, collective identity, space. 


\section{Introducción}

$\mathrm{E}$

1 movimiento estudiantil de 1968 en México representa un suceso histórico y memorístico insoslayable en la lucha por la construcción democrática. Constituido por una red de alianzas sociopolíticas entre escuelas y universidades públicas y privadas, este sujeto encerró numerosas prácticas deliberativas y decisorias no sólo al interior de su máxima instancia, el Consejo Nacional de Huelga $(\mathrm{CNH})$, sino también dentro de cada una de las escuelas que lo conformaban. Hablar del 68 implica considerar que en las instituciones educativas se ejerció una forma específica de politicidad. - La Escuela Preparatoria Técnica Piloto Cuauhtémoc del Instituto Politécnico Nacional (IPN) conocida como la Vocacional 7- es un caso emblemático no sólo por su alta participación durante el 68, sino por la existencia de un conjunto de antecedentes organizativos y de un sentimiento de pertenencia que, en cierta forma, abrevaron en el movimiento estudiantil. El presente artículo es un análisis desde la sociología de los movimientos sociales y desde la geografía política y la cultural sobre cómo se construyó la acción colectiva en esta institución; los antecedentes sociopolíticos que contribuyeron a la movilización del 68; el papel que desempeñó el espacio en la construcción de la identidad de sus estudiantes, así como lo que significa esta escuela para sus exalumnos. Así, el artículo está estructurado en seis secciones: en la primera, se expondrá la estrategia metodológica empleada; en la segunda, una serie de lineamientos teóricos sobre el espacio como construcción social; en la tercera, se abordará la gestación de la Vocacional 7, cómo los alumnos fueron esculpiendo la identidad colectiva, así como los principales espacios de interacción social; en la cuarta, la acción colectiva en esta escuela durante 1968; y, en la quinta, la clausura de este proyecto educativo y sus implicaciones sociopolíticas. Finalmente, se presentarán las conclusiones.

\section{Lineamientos metodológicos}

Con el fin de analizar la relación entre espacio, acción colectiva e identidad en la Vocacional 7 durante la movilización de 1968, se aplicaron dieciocho entrevistas a profundidad a exestudiantes de esta institución, tanto del turno matutino como del vespertino, participantes en este movimiento social - hombres y mujeres; líderes y bases con diversas posturas políticas - amén de una revisión bibliográfica y hemerográfica. La elección de los informantes se efectuó, en algunos casos, por bola de nieve y, en otros, se buscó expresamente conocer el testimonio de ciertos actores destacados en este conflicto sociopolítico. El objetivo de las entrevistas fue recoger y contrastar testimonios acerca de la construcción de la movilización colectiva y la identidad; la vida sociopolítica previa al 68; los principales lugares de interacción social al interior de esta escuela; y las formas de apropiación material, política y simbólica de dichos espacios durante este movimiento. Además, los informantes realizaron mapas mentales de la Vocacional 7 con la finalidad de identificar los principales lugares de la memoria. En suma, se realizó una investigación de carácter cualitativo en la que la

experiencia sociopolítica y la relación sujetos-espacio constituyen el núcleo de análisis sociológico y geográfico. 


\section{El espacio como constructo social: algunos lineamientos teóricos}

El espacio y el tiempo juegan un papel cardinal en la articulación, reproducción y transformación de las sociedades y, como tal, representan categorías de análisis ineludibles. Como se sabe, el tiempo ha sido objeto de múltiples reflexiones filosóficas y sociológicas, interés analítico en parte delineado por la racionalidad moderna que se enfocó en desarrollar una concepción sobre lo temporal de forma lineal y teleológica. Tanto el espacio como el tiempo son construcciones sociales, históricas y culturales, que en la misma medida en que son constituidos, las sociedades van autoerigiéndose. Ambos son estructuras sociales estructuradas y estructurantes de un sinnúmero de procesos, relaciones, prácticas, acciones, instituciones y subjetividades. Como dimensiones constitutivas de la vida social - en sus diferentes escalas - tanto el espacio como el tiempo son edificados, percibidos, usados y representados de forma distinta por los grupos sociales, variables como el género, la clase social, la edad y la etnia inciden en las diversas formas de experimentar lo temporal y lo espacial. En este tenor, el espacio y el tiempo representan una dupla indisociable:

Hay razones suficientes para defender la idea de que tiempo y espacio constituyen dimensiones inseparables, tanto en el mundo físico, como en el social. Es obvio que la fisonomía temporal de la realidad sólo puede darse en el espacio y que este, en tanto espacio social, no puede ser imaginado, creado o construido sino en lapsos y mediante ritmos que atañen a la temporalidad social. Pero afirmar que el espacio y el tiempo son indisociables no significa postular que sean indiscernibles. De hecho hay argumentos sólidos en torno a la naturaleza diversa de cada una de estas dimensiones. (Valencia, 2007, p. 42)

Como lo muestra este escolio, la realidad social está espacializada y temporalizada. No obstante es factible, con fines exclusivamente analíticos, hacer una distinción conceptual entre tiempo y espacio sin que ello suponga olvidar que dicho maridaje - la espaciotemporalidad - mantiene un vínculo inquebrantable y recursivo con el mundo social. Como se ha sostenido, en este artículo me centraré en el rol que desempeñó el espacio tanto en la construcción de la identidad colectiva como en la dinámica de organización sociopolítica en los estudiantes de la Vocacional 7, durante el movimiento estudiantil de 1968. Por lo tanto, en este apartado desarrollaré un conjunto de lineamientos teóricos sobre el espacio que fungirán como puntos de partida en el análisis que atravesará este trabajo.

Reconocer que el espacio es un constructo social supone una mirada que lo des-naturaliza en aras de comprender cómo lo histórico, político y cultural se imbrican en su constitución. Lefebvre (2013) señalaba que todo modo de producción confeccionaba una forma espacial, amén de establecer tres conceptos - enlazados dialécticamente- que revelan cómo el espacio es concebido, percibido y vivido: la representación del espacio, la práctica espacial y el espacio de representación. Se puede inferir que, con esta aserción, Lefebvre alude a cómo la razón, los sentidos, las emociones y la construcción de sentido participan en la producción de lo espacial. En consecuencia, una gran diversidad de sujetos - desde arquitectos y urbanistas hasta actores legos-- edifica y transforma espacios a partir de factores culturales, condicionamientos históricos y variables políticas y económicas. 
Uno de los desafíos analíticos reside en cómo leer en el espacio indicios societales, dado que el vínculo espacio-sociedad no es lineal ni transparente. Sobre dicha relación apunta Harvey:

Un lugar concreto es una forma de ubicar historias, recuerdos y sueños. Conecta al pasado, con el presente y lo proyecta hacia el futuro. Un lugar puede investirse de significado simbólico de diversas formas: incorporando alusiones arquitectónicas en el diseño, sirviendo como telón de fondo de hechos clave ... su poder es un síntoma de la propensión humana a pensar mediante sinécdoques; la sala de trabajo se convierte en representación del socialismo y la justicia, al igual que la bandera roja. Es una catexis del deseo de transformación. El entorno físico es la realización, la encarnación, la materialización de la mitología política. (Harvey, 2017, p. 183)

El espacio cuenta con una dimensión material y con una simbólica, ambas interrelacionadas. En él se inscribe la dinámica del poder que lo utiliza como un canal para legitimarse, sacralizarse y reificarse. Lo espacial juega un rol notable en los procesos de movilización sociopolítica, en la construcción identitaria y memorística. Una mirada constructivista enfatiza que el espacio no es un simple escenario de la acción social. Así Lussault (2015) sostiene que los operadores espaciales o actantes humanos — sujetos individuales y colectivos- y los no humanos - como artefactos, objetos, animales, virus - realizan acciones de diversa naturaleza no sobre el espacio, sino con el espacio. Esta afirmación permite deducir que no solamente no existe un hacer aespacial, sino que en muchas ocasiones la espacialidad es un componente de la misma acción.

Según Harvey (2017) en la historia del pensamiento han existido tres concepciones del espacio: el absoluto, el relativo y el relacional. La primera lo define como algo fijo, cuantificable e inalterable, es la noción de Newton y de Descartes. En el ámbito de lo político y lo económico alude al Estado-Nación y a la propiedad privada. La segunda se refiere al cambio, los procesos y flujos, así como a los movimientos de personas, capital y bienes; corresponde a la noción de Einstein y a las geografías no euclidianas desarrolladas a fines del siglo XIX. Finalmente, el espacio relacional se vincula con las relaciones sociales -incluyendo las de poder - la memoria y la identidad. En el siguiente apartado, se analizará la construcción de la Vocacional 7 y la vida cotidiana como un marco espaciotemporal donde los estudiantes erigieron una identidad colectiva.

\section{La Vocacional 7 en Tlatelolco: vida cotidiana e identidad colectiva}

La historia de la Vocacional 7 inició en 1963 cuando comenzó a funcionar en lo que posteriormente fue la sede de la Vocacional 5 (Cedeño, 2003). Hacia 1964 fue reubicada dentro de un proyecto urbanístico que transformó socioespacialmente al norte de la Ciudad de México: la Unidad Habitacional Nonoalco Tlatelolco. Localizada en San Juan de Letrán -hoy Eje Central- esta institución quedaba al norte de la Plaza de las Tres Culturas. La Vocacional 7 junto con 102 edificios residenciales, once escuelas preprimarias, ocho primarias, tres secundarias, locales comerciales, centros deportivos y clínicas formaban parte del paisaje urbano tlatelolca (Cantú, 2001) (ver mapa 1). 


\section{Mapa 1}

Localización del predio donde se ubicaba la Vocacional 7

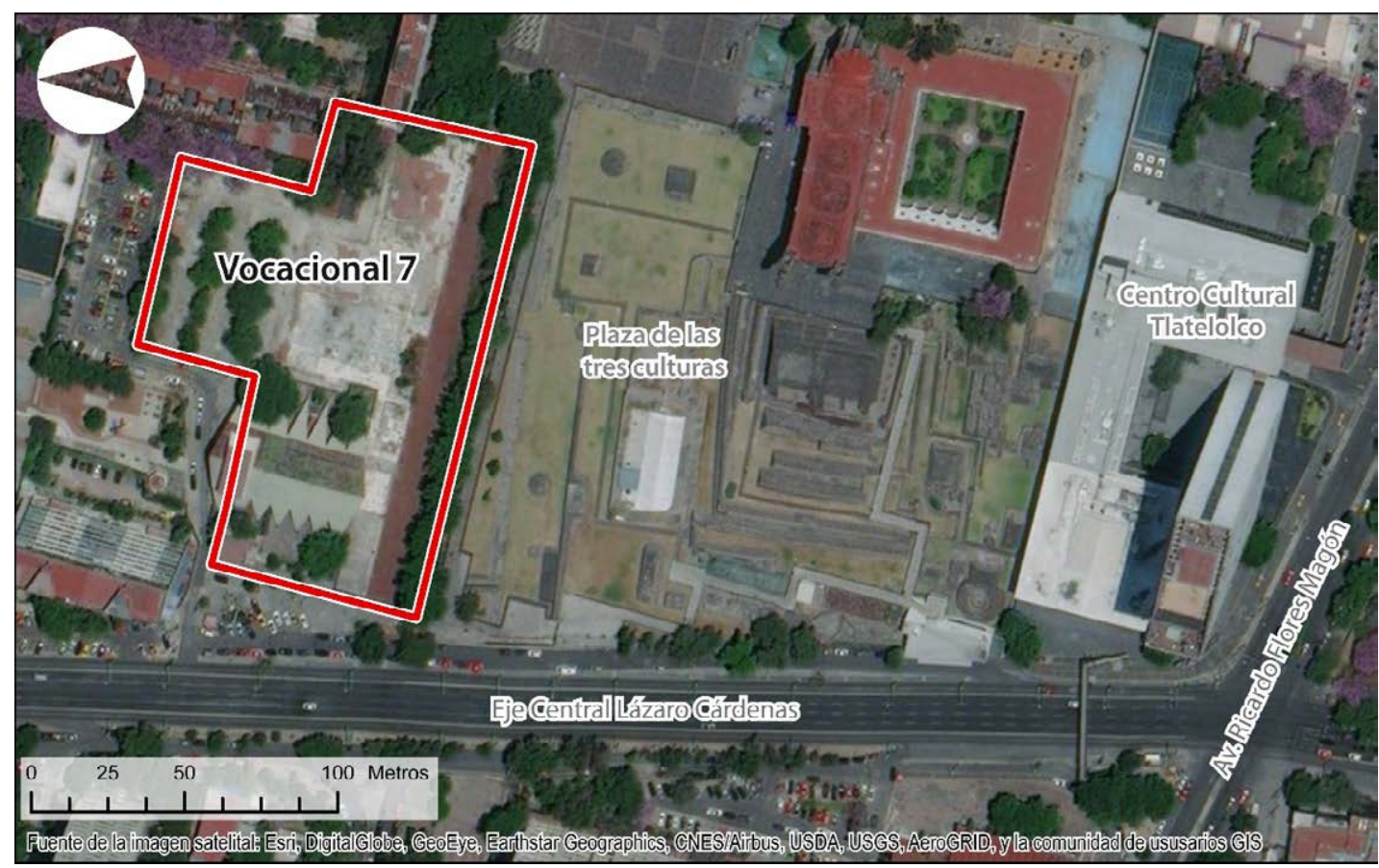

Fuente: Construcción propia.

La edificación de la Unidad Habitacional Tlatelolco y de la Vocacional 7, a cargo de Mario Pani, corresponden a lo que Lefebvre (2013) denominó la representación del espacio. La planeación y configuración de esta zona llevaba la impronta de la modernización del país y del llamado milagro mexicano, esto muestra cómo el espacio es producto de una intencionalidad social y política y, por ende, nunca es neutro.

La Vocacional 7 fue concebida como un proyecto educativo sui generis para el IPN, donde a diferencia de otras vocacionales, en ésta se concentraron tres áreas de conocimiento: fisicomatemáticas, ciencias sociales y ciencias biológicas. El propósito era una educación integral y humanista en donde se impartían materias como Psicología, Literatura, Sociología y Oratoria, en el turno matutino y en el vespertino. Al respecto habla Beatriz, alumna del turno matutino:

Nos pasábamos el día en la Vocacional porque había múltiples actividades que realizar: deportivas, como la esgrima. Hubo mucha formación integral porque tenías de todo, además los maestros eran de muy buen nivel, sí eran exigentes, pero sin ser autoritarios, yo siento que era una formación más humanista, no era una cuestión de aprender- aprender, sino de ¡razónalo! Teníamos un maestro de historia del arte buenísimo que no sólo nos daba historia del arte, sino también lo que en la preparatoria equivale a "Ética, lógica, etimologías", era una mezcla esa materia. Mucha gente que criticaba que las vocacionales eran sólo educación técnica, no, al menos en la Vocacional 7, tenía el toque humanista. (B. Juárez, comunicación personal, 25 de abril de 2019). 
El quehacer académico se acompañaba de diversas actividades culturales - como teatro y cine- y deportivas -como atletismo, futbol y esgrima-. Algunos de estos eventos eran organizados por los Ateneos - grupos estudiantiles existentes en varias escuelas del IPN-. Asimismo, se efectuaban competencias de matemáticas y física con otras escuelas, donde usualmente los alumnos de esta Vocacional obtenían los primeros lugares. Todas las actividades políticas, culturales, académicas y deportivas eran prácticas que formaban parte de la cotidianeidad de los alumnos de ambos turnos. Hablar de la vida cotidiana supone referirse a una edificación social donde prácticas y relaciones sociales, rutinas, significados y un sentido de lo aproblemático contribuyen a su confección. Berger y Luckmann (2002) caracterizaban a la cotidianeidad como la realidad suprema y enfatizaban en cómo es un terreno de intersección social articulado espaciotemporalmente. Durante su estancia en la Vocacional 7, los estudiantes forjaban lazos sociales y afectivos estrechos. Diferentes informantes han mencionado la relación de confianza entre profesores y alumnos; amén de los lazos de amistad desarrollados entre la comunidad estudiantil. El hecho de que el primer año de clases fuera de tronco común posibilitaba que se entablaran vínculos de camaradería que, en cierto modo, abrevaron durante el 68. Evidentemente, tanto las relaciones sociales como las prácticas estaban espacializadas. De este modo, relacionalidad, prácticas socioespaciales, significados y experiencia fueron macerando un sentido de pertenencia a la Vocacional 7 y con ello la articulación de la identidad colectiva:

A mí me encantaba ir a la Vocacional 7 porque además tuve un círculo de amigos muy amplio ... Creo que fue la mejor elección que pude hacer irme a estudiar a esta Vocacional. Me sentía totalmente integrada, me sentía en mi ambiente. (M. Frías, comunicación personal, 4 de junio de 2019).

La identidad colectiva es un artificio social delineado espaciotemporalmente que encierra cuatro vectores: pertenencia, permanencia, reconocimiento y otredad (Tamayo y Wildner, 2005). Resulta cardinal señalar que ninguna identidad es algo fijo, por lo contrario, es un proceso cambiante - pese a la relativa estabilidad que puede contar- La configuración identitaria se da en dos planos: a) a partir de las relaciones que sostengo con otros sujetos; $\mathrm{y} b$ ) en virtud de los diferentes espacios en los que interactúo y con los que me vinculo. Así, particularmente en las sociedades modernas, se gesta un sentido de pertenencia a diversos grupos sociales y a varios espacios, simultáneamente. Esto implica que existe una relación íntima entre espacio e identidad, de manera tal que un cambio en el primero puede detonar una transformación identitaria, y viceversa. En el caso de la Vocacional 7, la dupla espacio-identidad se cristalizaba en función de las prácticas y las formas de relacionalidad: "me sentía parte de la Vocacional pues por la participación que tenía en las actividades: en las clases, en la cafetería, con los maestros, con los compañeros" (B. Juárez, comunicación personal, 25 de abril de 2019). Referirse al nexo espacio-identidad supone hablar de sujetos territorializados y territorios subjetivados. Como bien afirma Lindón (2000) los actores no sólo están territorializados, sino que también son territorializados.

¿Qué espacios al interior de la Vocacional 7 son los más recordados en virtud de las prácticas realizadas y de la interacción social e identitaria? En primer lugar: "el auditorio era muy bonito, moderno, modernísimo, muy lujoso por dentro, con butacas muy bonitas, grande, fino, con escenario. Ahora es un teatro (Teatro Isabela Corona)" (C. Cortés, comunicación personal, 19 de junio de 2019). Sobre otros recintos: 
Yo creo que todos los espacios, porque la escuela era mi segunda casa, o mi primera, ya no sé. Recuerdo mi aula, era el jefe de grupo y además yo quería ser el mejor estudiante. La imagen del aula es una de las primeras que vienen a mi mente. Otra la del campo deportivo, yo corría prácticamente todos los días, cinco kilómetros, todos los días. Yo usé muy bien las instalaciones de la Vocacional 7, no creo que haya alguien más que las haya usado más que yo ... Para mí la escuela lo fue todo, la Vocacional 7 me hizo crecer muchísimo. El auditorio ni se diga, ahí nos reuníamos en el 68 para dirigir asambleas o para participar en ellas, o en el comité de lucha, participando como brigadista o como organizador o como dirigente. (F. Posadas, comunicación personal, 19 de junio de 2019).

Uno de los lugares más citados por los entrevistados — hombres y mujeres - estuvo permeado por una concepción de género:

El que me fascinaba era "El salón de damas", le llamábamos así. A medio pasillo, del primer piso, había un salón que tenía como una mesa de juntas al centro; tenía varios armarios y dos sillones grandísimos, uno en la pared y el otro del otro lado de la mesa. Tú podías llegar a estudiar o a compartir con alguien de ahí del Salón de Damas. La señora que nos atendía era la señora Helenita, a quien veía grande de edad. Te cuento casos que vi: chicas que llegaban en el mar de llanto: “es que me cortó mi novio...” Y la señora Helena les decía, “A ver, siéntate, tú tranquila”, les ofrecía un dulce; o bien llegabas con el cólico menstrual y la señora nos daba una pastilla para el dolor. Es decir, era un salón de damas, como le llamaban, no sé por qué ... porque éramos alumnas, chavitas, y nos trataban, como a unas damas. (G. Preza, comunicación personal, 28 de abril de 2019).

En este tenor, el auditorio, las aulas, la entrada a la Vocacional, el mirador -que daba a la Plaza de las Tres Culturas- los laboratorios, las canchas deportivas, la cafetería, la biblioteca son algunos de los sitios más recordados por los entrevistados. En cada uno de ellos se desplegaban diversas prácticas socioespaciales y distintos lazos sociales. Siguiendo a Lefebvre, se trata de representaciones del espacio, concebidos y proyectados por arquitectos e ingenieros con una función material y social específica. No obstante, también son espacios de representación, apropiados material y simbólicamente que en contraste con lo afirmado por Lefebvre, quien asevera que estos son experimentados de forma pasiva-fueron vividos y significados activamente por los agentes. Heidegger (1994) mencionaba que el habitar va más allá de la residencia; un espacio es habitado cuando representa protección, confianza y sentido. A manera de hipótesis, sostengo que la Vocacional 7 fue un espacio habitado, practicado y significado cotidianamente antes del movimiento estudiantil de 1968 y durante el mismo.

Uno de los conceptos más sugerentes para comprender la experiencia espacial sellada por vectores sensoriales, emocionales, simbólicos y relacionales es el de topofilia, erigido por Yi Fu Tuan (2007). Se trata de aquellas manifestaciones de apego al lugar, condicionadas cultural e históricamente. Tuan asevera que si bien existen factores biológicos que universalizan las capacidades sensoriales de los individuos, la percepción está delineada culturalmente. Para este geógrafo, la topofilia comprende desde la sensación de bienestar, hasta un sentimiento profundo de apego al lugar: 
La escuela era muy agradable, los salones eran muy amplios, eran muy bonitos, la construcción era muy bonita porque había mucha vista hacia la Plaza de las Tres Culturas; el espacio era maravilloso, sobre lo que era antes San Juan de Letrán. Pero la vista hacia la Plaza de las Tres Culturas es algo que a uno no se le olvida (M. Frías, comunicación personal, 4 de junio de 2019).

En el siguiente testimonio se destaca a la Vocacional como esfera de experiencia:

Representó un núcleo que aglutinaba, que me transformó de una manera significativa. Quiero decirte que en la actualidad conservo muchos amigos de la Vocacional 7, que ahí estudiaron. De alguna u otra forma, la Vocacional 7 significó para mí y para muchos más, un espacio muy formador, de mucha experiencia vivencial y política. (J. García Reyes, comunicación personal, 27 de febrero de 2019).

Asimismo, la Vocacional 7 ha sido significada por algunos de sus exalumnos en una vertiente afectiva: “(al recordar la Vocacional) todo, se agolpa muy fuertemente... es que no te lo puedo decir, no se puede decir, no, es muy difícil. Tendría que haber muchas sesiones, muchos recuerdos, para que uno entre en un estado de recordación que no le gane la emoción” (J. Vázquez, comunicación personal, 25 de febrero de 2019).

La topofilia experimentada por los estudiantes se vincula con lo que Lussault (2015) define como valor espacial, el cual es el conjunto de cualidades socialmente valorizables de un espacio. Esta noción tiene una connotación constructivista y dinámica:

La cuestión del valor remite, pues, al análisis de las condiciones sociales generales y a la condensación en las disposiciones espaciales de valores (positivos y/o negativos) por los actores sociales. Esta condensación -tanto física, en objetos materiales particulares, como ideal, en ideologías y representaciones- valoriza el espacio y espacializa los valores, confiriéndoles así un registro específico. Dicho fenómeno inyecta el espacio en el universo del sentido, e inscribe el sentido en la dimensión espacial. (Lussault, 2015, p. 173).

De esta manera, la topofilia vivida por los alumnos de la Vocacional 7 encierra un proceso de valorización social de este lugar, labor fundamentada en la experiencia. En otras palabras, el apego a esta escuela llevaba implícitamente un trabajo de significación del espacio — de valoración positiva - en virtud de la experiencia, las relaciones sociales y políticas y las prácticas desarrolladas cotidianamente.

Sostengo que hay una relación cercana entre topofilia, identidad colectiva y la dinámica de valoración social: experimento apego a un lugar en función de que me siento parte de él y del grupo social que en interacción lo erige; esta emoción encierra un proceso de significación social del espacio. Por consiguiente, uno de los componentes que nutrió la topofilia en la Vocacional 7 fue la identidad colectiva; de manera semejante, la topofilia puede ser vista como un indicio identitario. Otros ingredientes topofílicos fueron la satisfacción de los alumnos por la formación académica; las relaciones sociales entabladas entre los estudiantes y de estos con los profesores; el placer estético frente a la configuración arquitectónica y, como veremos, la vida política. En suma, la experiencia es el núcleo de la topofilia. En el siguiente apartado se analizará la forma en que se edificó la acción colectiva en esta escuela durante el 68. 


\section{La construcción de la acción colectiva en la Vocacional 7 durante el 68}

Los movimientos sociales son un tipo de acción colectiva donde existe un conflicto sociopolítico, en el que se articula, o rearticula, una identidad colectiva y donde individuos organizados - a partir de objetivos en común- despliegan en el espacio público repertorios de confrontación, o sea métodos de lucha pergeñados cultural e históricamente, con los que se busca visibilizar la movilización y las demandas y replegar al adversario. Como señala Revilla (1994), los movimientos engloban acción, identidad y sentido dentro de un cauce no institucional. Es el campo de confrontación hilvanado por los actores y sus adversarios el elemento clave para comprender a la movilización social. Para Touraine, dicho conflicto "es también y ante todo una relación de dominación" (Touraine, 1995, p. 260), aserto con el cual este sociólogo subraya la asimetría existente entre los individuos organizados y sus oponentes. Los movimientos sociales son un desafío colectivo donde la producción de significados al interior del sujeto y la dirigida tanto a los oponentes como a la audiencia juega un papel nodal, es decir, los sujetos enmarcan, resaltan, parcelas de la realidad que, a juicio de los agentes movilizados, está sellada por la injusticia. Todo actor colectivo es un proceso, y no una sustancia, en la medida en que es fruto de la interacción social y de la misma dinámica del conflicto.

Justamente, el movimiento estudiantil de 1968 constituyó un desafío a un régimen político autoritario donde el corporativismo y el clientelismo eran mecanismos de control político ante cualquier expresión opositora. Si se parte de la premisa que la movilización no es una sustancia sino una construcción social, entonces habría que subrayar que el 68 fue producto de una red de alianzas y solidaridades entre las diversas universidades y escuelas participantes, donde pese a la pluralidad de posturas políticas había un marco común: los seis puntos del pliego petitorio y la oposición a la cerrazón y autoritarismo del gobierno encabezado por Gustavo Díaz Ordaz.

En el caso de la Vocacional 7, la acción colectiva durante el 68 contó con una serie de antecedentes que fungieron no solamente como referentes identitarios y organizativos, sino además como un terreno de autonomía sociopolítica necesario para la edificación del movimiento. Una parte fundamental de la vida política en esta escuela previa al 68, fue la heterogeneidad de grupos estudiantiles con diferentes afinidades políticas: como la Juventud Comunista —adscrita al Partido Comunista_ la Liga Espartaquista, la Asociación de Jóvenes Esperanza de la Fraternidad (AJEF) — masones que para ese entonces tenían presencia en varias escuelas del IPN - y simpatizantes del Partido Revolucionario Institucional (PRI). Diversas actividades políticas y culturales eran organizadas por dichas agrupaciones como parte de su quehacer militante.

Una de las esferas más importantes de la organización colectiva en esta Vocacional - y en el grueso de las instituciones politécnicas - era la participación en los sufragios para elegir a los representantes de la Sociedad de Alumnos. Por décadas esta instancia fue monopolizada por la Federación Nacional de Estudiantes Técnicos (FNET), constituida en 1937. Si bien la FNET jugó un rol notable en las movilizaciones de 1942, 1950 y 1956 al interior del IPN (Álvarez Garín, 2002), años más tarde se convirtió en un instrumento de control político hacia un sector que, a diferencia de los obreros y los campesinos, no estaba formalmente corporativizado: el estudiantil. De este modo la FNET, al ser una esfera de representación de alumnos de todas las escuelas técnicas del país, cooptaba y obedecía a los lineamientos de las autoridades 
escolares y del propio régimen priista, contando con recursos económicos y políticos abundantes provenientes de las más altas esferas del poder.

Hacia 1968, planillas de ambos turnos de la Vocacional 7 opositoras a la FNET ganaron las respectivas Sociedades de Alumnos, siendo elegidos presidentes José Nasar — de las AJEF - en la mañana y Jesús Vázquez — de la Juventud Comunista - en la tarde. La crisis de legitimidad de la FNET no sólo se dio en esta Vocacional, sino también en otras escuelas politécnicas que lograron erigir una representación estudiantil independiente, como la Escuela Nacional de Ciencias Biológicas, la Escuela de Medicina Homeopática, la Escuela Superior de Economía, y el Centro de Estudios Científicos y Tecnológicos Wilfrido Massieu. Así, se fue forjando un bloque sociopolítico autónomo de gran valía para la postrera acción colectiva del 68. Cabe resaltar que el clima político previo a dicho movimiento, en muchas escuelas del IPN y de la UNAM, estaba sellado por la presencia de la Juventud Comunista.

Otro antecedente sociopolítico importante fue la huelga estudiantil de 1967. Su nacimiento se dio en la Escuela Superior de Agricultura Hermanos Escobar, en Ciudad Juárez, Chihuahua, cuando un grupo de alumnos realizó un paro con el objetivo de contar con un profesorado mejor preparado y más actividades profesionales. Las autoridades respondieron encarcelando a los líderes, situación que detonó otra demanda del movimiento: la federalización de la escuela y con ello pasar de ser una institución privada a una pública. La ausencia de una respuesta gubernamental provocó que estudiantes de la Universidad de Chapingo y de varias escuelas politécnicas - entre ellas la Vocacional 7 en su turno vespertino- se solidarizaran efectuando una huelga. Finalmente, el gobierno de Díaz Ordaz cumplió con las demandas planteadas, tras una semana de paro estudiantil.

Pese a la brevedad de la movilización del 67, esta representó un referente relevante:

Los enfrentamientos que tuvimos nunca fueron en la escuela, poníamos nuestras barricadas y teníamos palos para defendernos, pero nada más, nunca se dio ahí, íbamos al centro y ahí nos madreaban, en las manifestaciones. En el 67 hay una respuesta politécnica, esa respuesta politécnica es un movimiento que duró una semana, pero que cohesiona dirigentes, cohesiona activistas, cohesiona organización. (F. Galván, comunicación personal, 8 de febrero de 2019).

La reverberación sociopolítica del 67 se desplegó en dos dimensiones: en primer lugar, durante dicha movilización se efectuaron repertorios de confrontación que un año más tarde serían desplegados: como brigadas informativas y brigadas para recabar dinero, guardias, mítines, barricadas, huelgas y particularmente se construyó un órgano deliberativo y decisorio, el Consejo General de Huelga (Álvarez Garín, 2002) que en el 68 transmutó en el CNH. En segundo, el 67 posibilitó la formación de una red de alianzas sociopolíticas y solidarias entre diversas escuelas, como la forjada entre la Universidad de Chapingo y diversas instituciones politécnicas que se oponían al control de la FNET, incluyendo la Vocacional 7.

Los estudiantes de esta Vocacional también participaron en la Marcha por la Libertad organizada por la Central Nacional de Estudiantes Democráticos (CNED) — adscrita al Partido Comunista — en febrero de 1968. La finalidad era repetir la ruta efectuada por Miguel Hidalgo durante la guerra por la independencia, demandando la liberación de los presos políticos. Pese a que esta marcha fue reprimida por el ejército, constituyó otro precedente de experiencia organizativa y de referente de sentido (C. Cortés, comunicación personal, 4 de marzo de 2019). 
La participación en la huelga de 1967 y en la Marcha por la Libertad, junto con la oposición a la FNET, conformaron lo que defino como un saber organizativo y de resistencia que redundó en el movimiento de 1968. Me refiero al conjunto de habilidades, conocimientos, destrezas y experiencias que un sujeto colectivo labra intersubjetivamente dentro de un campo de confrontación sociopolítico sostenido con un adversario. Recuperando a Schutz y a Luckmann (2003), este saber constituye un acervo de conocimientos que puede también ser articulado a partir de la transmisión de experiencias colectivas de otros actores, con otras demandas. Todo saber organizativo y de resistencia es un constructo social permeado por una cultura política, o sea, por valores, ideas, creencias, emociones y razones sobre el poder, sus formas e instituciones. La articulación de este acervo de conocimientos comprende un ejercicio de memoria, es decir, la interpretación de sucesos pasados realizada desde las necesidades, problemas y expectativas actuales. El conflicto y movilización vividos en el presente se convierten, así, en otra fuente del saber organizativo $y$ de resistencia - en otro referente de sentido-al cual se podrá recurrir en confrontaciones futuras. Los repertorios de confrontación, las dinámicas deliberativas y decisorias, así como los procesos de negociación con los oponentes son prácticas en las que este acervo es abrevado.

La movilización estudiantil de la Vocacional 7 en 1968 inició el 27 de julio, cuando la asamblea general acordó la huelga tras la represión del día anterior. Cabe recordar que el 26 de julio fueron realizadas dos marchas: la primera convocada por la FNET cuyo objetivo era protestar por la toma policiaca de las Vocacionales 2 y 5 y por los actos de violencia de tres días antes, y cuya ruta estaba planeada de la Ciudadela, al Casco de Santo Tomás. La segunda, fue encabezada por la CNED en apoyo a la revolución cubana y cuyo trayecto era del Salto del Agua, al Hemiciclo a Juárez. Ambas manifestaciones fueron reprimidas por el cuerpo de granaderos, detonando el agravio entre la comunidad estudiantil de diversas universidades y escuelas.

Una vez iniciada la huelga en la Vocacional 7, las sociedades de alumnos de ambos turnos mutaron en comités de huelga. Aunque alumnos de los dos horarios se incorporaron al movimiento, los de la tarde se distinguieron por una mayor participación y por desempeñar un liderazgo en numerosos procesos organizativos. Al igual que en otras escuelas, las asambleas eran la principal esfera de discusión y decisión colectiva. Tanto el turno matutino como el vespertino contaban con una, además de existir la asamblea general. La huelga de los dos turnos exigió el despliegue de repertorios como las guardias y las barricadas orientadas a proteger el edificio. Marchas, mítines relámpago, comisiones, y comités fueron otros métodos de lucha relevantes.

Si en algún repertorio se destacaron los activistas de la Vocacional 7 - por su cantidad y nivel organizativo- fue en las brigadas informativas, así como en las brigadas encargadas de recabar dinero:

Yo daba 50 botes que me tenían que firmar tres responsables, cuando ellos regresaban con el bote lleno de dinero yo los tachaba, les recibía el bote, entonces ¿cómo se organizaban ellos? Eso era una situación bien aleatoria entre ellos. Yo supe que en uno de los camiones del Poli se llegaban a ir 3 o 4 botes en el mismo camión, y éste hasta el tope de gente, y se iban a las fábricas de Manuel González, a hacer mítines relámpago o a la Lagunilla o a Tepito ... No sé quién fue a levantar a la Ibero, pero sé que una de las brigadas fue allá, llegaron así con los botes y empezaron a repartir volantes. Con ese dinero, compré varios megáfonos, muchos se perdieron. (I. Uranga, comunicación personal, 10 de febrero de 2019). 
Las brigadas informativas cumplían con la labor de enmarcar las demandas del actor y de dar a conocer el desarrollo del conflicto - en un momento histórico donde la mayoría de los medios de comunicación reproducían la versión oficial- mientras que gracias al boteo se obtenían recursos económicos encaminados a comprar alimentos e insumos varios y otorgar dinero al $\mathrm{CNH}$, quien en varias ocasiones recurrió al comité de huelga de esta Vocacional para pagar desplegados en periódicos como Excélsior y El Día (F. Galván, comunicación personal, 8 de febrero de 2019). En consecuencia, las brigadas erigidas en esta escuela no sólo revestían de importancia organizativa y gestiva para ella misma, sino para el grueso del movimiento estudiantil.

Explorar la dupla espacio-acción colectiva supone trascender la mirada del locus como simple escenario de la movilización. Para Lussault (2015) el espacio es un recurso, planteamiento a partir del cual sostengo que lo espacial es un recurso de movilización. Los repertorios implementados por los estudiantes de la Vocacional 7 implicaban un proceso de (re)apropiación material, simbólica y política del espacio. Así, las asambleas se llevaban a cabo en un lugar emblemático de las prácticas culturales y recreativas: el auditorio. En el caso de las barricadas y las guardias, resulta claro que su realización respondía a la necesidad de resguardar las instalaciones de la Vocacional 7, de ahí que se efectuaran en sitios estratégicos como a la entrada de la escuela y de la cafetería —en el caso de las primeras - y en la azotea, las segundas. Sobre las brigadas, la razón que guiaba dónde se hacían se fincaba no sólo en la cercanía espacial, sino también en la social:

Cuando uno organiza una brigada, a los lugares a los que va es a los lugares más cercanos y así se van haciendo una especie de círculos concéntricos. Nuestros lugares aledaños, aparte de Tlatelolco — donde vivía la burocracia - eran las colonias Guerrero, Peralvillo, Tepito, zonas muy populares y luego todo el norte de la Ciudad de México, el norte industrial, Vallejo, Azcapotzalco, ahí íbamos. Esto era así, en parte por la composición de clase de los estudiantes del IPN. Ahí se podía apreciar también las diferentes raíces y pertenencia de clases sociales de los estudiantes del Poli y de la UNAM. Los del Poli tenían fama de ser más combativos, participar más en las brigadas, con más combatividad y resolución, dedicación. (F. Posadas, comunicación personal, 19 de junio de 2019).

Aludir a la forma en que se relacionan el espacio y los movimientos sociales, supone reconocer que estos a través de su discurso, de su enmarcado, y de diversas acciones, como los repertorios, contribuyen a la edificación del espacio público. Este concepto, no obstante, hay que comprenderlo en un doble sentido:

El espacio público se ha asociado a los espacios abiertos de las ciudades modernas. Y así se ha desvanecido el carácter fundamentalmente político del concepto original. Eso ha hecho que algunos geógrafos y urbanistas reprochen el carácter ambiguo del término, y responsabilicen a los científicos sociales, principalmente de las ciencias políticas, de manipular el término espacio al referirse a la esfera pública. Al contrario, estudiosos de la esfera pública han criticado ciertas posiciones de los estudios urbanos, que reducen el concepto de esfera o espacio público al uso y disfrute cotidiano en espacios urbanos abiertos. (Tamayo, 2016, pp. 111-112) 
Sintetizando, no se puede hablar del espacio físico sin considerar su dimensión política, y viceversa. En consecuencia, el espacio público se despliega en dos planos interrelacionados: como arena de discusión y como terreno. El espacio público es una construcción histórica marcada por el conflicto, por una pluralidad de actores que cuentan con diversos proyectos y visiones sociopolíticas y axiológicas; heterogeneidad de clase, de género, cultural, identitaria y etaria coexisten en el espacio público que, como baliza Tamayo, compete tanto al ámbito institucional como al no institucional. Gobierno, actores colectivos, partidos políticos y medios de comunicación son agentes insoslayables en su edificación (Tamayo, 2016).

Por otra parte, los sujetos colectivos a través de diversas modalidades de acción se apropian material, política y simbólicamente de numerosos sitios. Los jóvenes de la Vocacional 7 se (re)apropiaron de lugares al interior de la escuela, como el auditorio, la cafetería, la azotea, oficinas administrativas, las pistas deportivas y las aulas durante la huelga. Asimismo, se (re) apropiaron de diferentes espacios urbanos: calles, avenidas, mercados, teatros, cines, parques y camiones. Estos espacios apropiados que pueden ser clasificados como indoor - los primeros- y outdoor - los segundos- (Lindón, 2015) conformaron un entramado topográfico de la acción colectiva.

La huelga representó una ruptura de la cotidianeidad existente antes del 68 y su inherente espaciotemporalidad y sentido de normalidad. Evidentemente, las clases fueron suspendidas; numerosos estudiantes vivían en las escuelas al participar en diferentes actividades sociopolíticas. Sostengo que el conflicto no sólo quebrantó la espaciotemporalidad de la vida cotidiana, sino que configuró otra: una relativa al ritmo de la movilización social con sus rutinas, rituales, repertorios y formas de relacionalidad al interior del actor, con los aliados y con los adversarios.

Por otra parte, la Vocacional 7 fue objeto de diversos ataques por grupos de militares, paramilitares y granaderos. La capacidad de recabar recursos económicos — gracias a las brigadas - la cantidad de mimeógrafos disponibles; su ubicación geográfica - a ella arribaban estudiantes de otras escuelas para imprimir volantes, comer o a participar en actividades sociopolíticas-; la identidad colectiva de su comunidad y la capacidad organizativa de sus militantes eran recursos materiales, espaciales, simbólicos y políticos que le conferían a esta Vocacional de una especial relevancia, de ahí la coerción de la que fue blanco. En la madrugada del 30 de julio, el ejército tomó las instalaciones de la Vocacional 7 y entró a las Preparatorias 1, 2, 3 y 5 de la UNAM y a la Vocacional 5 (Valverde, 2018). El 31, el ejército abandonó a la Vocacional 7. El 29 de agosto, esta escuela fue embestida por paramilitares:

En la noche del 29 estábamos en la Vocacional 7, haciendo guardia. Tenía mucho sueño y les dije a mis compañeros que si pasaba algo me avisaran para correr. Entonces llegó el cuerpo paramilitar y todos salieron corriendo, me di cuenta que eran balazos, estaban ametrallando la escuela, entonces me preparé para salir corriendo y decidí salir por la parte de atrás, por la barda que daba a la Plaza de las Tres Culturas. Ahí me encuentro con parte del grupo paramilitar, jóvenes vestidos de civil, con casquete corto y armas de alto calibre, de uso exclusivo del ejército. Corro y me tumban, les dije que no era estudiante y entonces me insultaron y golpearon: “ino te hagas pendejo!”, me golpearon mucho con las culatas de los fusiles. Me iban golpeando por todo el barandal que daba a las ruinas de Tlatelolco, 
avanzamos y en la puerta de la subdirección de la escuela me tiran un balazo, con una bala expansiva, que queda alojada en la puerta de la subdirección. Entonces yo instantáneamente, sin tiempo siquiera para pensar, me caigo. No sabía si me habían dado o no. Los paramilitares siguieron avanzando porque era un ataque relámpago, disparando y tirando bombas molotov. Con una bomba parece que querían quemar el auditorio de la escuela y salen. Para eso, ya se habían prendido muchas luces de los edificios aledaños, principalmente del edificio Chihuahua. La gente le gritaba a los paramilitares: “¡Asesinos!” y toda clase de insultos (F. Posadas, comunicación personal, 19 de junio de 2019).

Los ataques contra la Vocacional obedecían a una estrategia gubernamental de desarticulación del movimiento dirigido al locus organizativo: las escuelas. Así, otras vocacionales y preparatorias, incluyendo al Colegio de México, fueron también baleadas por las madrugadas.

Si bien en asamblea los estudiantes de la Vocacional 7 acordaron resistir frente a la amenaza de los granaderos de tomar la escuela, la decisión fue salir si se trataba de militares. Ante los ataques, los jóvenes tuvieron que recurrir a su acervo de conocimientos espaciales para escapar. Me refiero al conjunto de conocimientos y habilidades erigidos por los sujetos con base en la experiencia en el espacio. Esta definición se asemeja al concepto de capital espacial de Lussault (2015), el cual es instituido e instituyente de diferentes prácticas sociales, capital que le confiere a los individuos la competencia para actuar, pensar y sentir. Así, los estudiantes apelaron al capital espacial labrado a partir de la experiencia dentro de la Vocacional y en zonas aledañas, acervo del cual los atacantes carecían. Al igual que los estudiantes, trabajadores de esta escuela, solidarios con el movimiento, recurrieron a dichos conocimientos:

Además de la puerta principal de la Vocacional, había dos atrás: una por donde estaba la cancha, y otra por unos laboratorios, eran puertas que nadie, o pocos, conocían. Como los trabajadores también estaban de alguna manera apoyando al movimiento, en una ocasión a mí me sacaron por una puerta por allá, por el sótano, en la parte de atrás que daba prácticamente hacia el jardín, donde está la rotonda. (B. Juárez, comunicación personal, 25 de abril de 2019).

No obstante, los alumnos en varias ocasiones resistieron utilizando bombas molotov y piedras, además de bloqueos y quema de camiones con la finalidad de defender su escuela. Uno de esos episodios fue el 21 de septiembre, cuando alumnos de esta Vocacional y estudiantes de otras instituciones del IPN — junto con habitantes de Tlatelolco- se enfrentaron a granaderos y militares quienes querían tomar dicha Vocacional. Los jóvenes consiguieron finalmente replegar a sus adversarios (Excélsior, 22 de septiembre de 1968).

Los enfrentamientos a ras del suelo entre fuerzas estatales y los estudiantes — no sólo de la Vocacional 7- evidencian el papel cardinal que juega el espacio en los conflictos sociopolíticos:

Todos los movimientos políticos, sociales y religiosos se valen de estrategias territoriales de construcción de lugar para alcanzar sus objetivos. Tanto las geografías de la libertad como las geografías de las represiones autoritarias recurren a dichas estrategias. Escapar de la lógica de la territorialidad y la construcción del lugar no es más posible que escapar de la política. (Harvey, 2017, p. 229) 
En consecuencia, la Vocacional 7 comprendida como un espacio físico, social, simbólico y político era objeto de disputa entre los agentes confrontados. Esto revela cómo la Vocacional fue valorada socialmente tanto por parte de los estudiantes movilizados, como por sus adversarios, valoración que respondía a racionalidades diferentes. Así como los repertorios realizados por el movimiento estudiantil tenían un carácter espacial, lo mismo sucedía con lo que llamo repertorios represivos implementados por el gobierno mexicano. Me refiero al conjunto de mecanismos legales e ilegales cuyo propósito era desmantelar al movimiento mediante acciones donde la espacialidad claramente operaba, como en la toma y los ataques a las escuelas; encarcelamientos a estudiantes; enfrentamientos callejeros y - posterior al 2 de octubre- la inoculación de porros en los centros educativos. Asimismo, hay que resaltar otros repertorios como las violaciones al debido proceso. Los repertorios represivos estaban marcados por una racionalidad estatal autoritaria.

Si la organización estudiantil tenía estrategias territoriales para visibilizar su lucha y replegar al adversario, y el gobierno mexicano también desplegaba recursos espaciales de desmovilización, del mismo modo varias expresiones solidarias hacia este actor tenían una implicación espacial. Remitirse a la solidaridad en los movimientos sociales, exige discernir analíticamente entre aquella que se construye en el seno del actor y la proveniente de otros sujetos —individuales y colectivos-. Ambas expresiones, implican una forma de relacionalidad social que en ocasiones puede desembocar - o bien ser un indicio- de la identidad colectiva.

Denominaré redes solidarias de corte espacial a aquellas manifestaciones de solidaridad a los estudiantes de la Vocacional 7, que se cimentaban en la contigüidad social y espacial. Con fines analíticos, distinguiré los diversos eslabones que constituyeron esta red. En primer lugar, está la solidaridad de habitantes de la Unidad Tlatelolco. Cabe destacar que varios estudiantes de esta escuela vivían en este conjunto habitacional, hecho que permite inferir que el apoyo se fincaba en la existencia de densos vínculos sociales, familiares y de amistad:

Nosotros no carecíamos de nada, porque la población de ahí nos llevaba fruta, comida, agua, hasta postres. Tlatelolco se había fundado poco tiempo atrás. Ahí vivía mucha gente del sector público, burócratas. Entonces los burócratas pues también tenían sus problemas, entonces se identificaban con nosotros muy bien. La gente nos estimaba mucho, nos consideraba como sus hijos. (M. Espinal, comunicación personal, 26 de marzo de 2019).

En segundo término, la represión de la cual eran objeto los alumnos generó entre los habitantes de Tlatelolco un sentimiento estrechamente ligado a la solidaridad: la empatía. Agustín Ramos quien, entonces vivía en esta unidad, en el edificio Baja California, da su testimonio:

Eran escaramuzas, desde el primer encuentro que hubo, la gente se puso del lado de los estudiantes por una razón muy simple: los estudiantes peleaban con lo que podían, los granaderos llegaban bien armados, iban de azul con casco y con protector y con sus toletes. Se iban corriendo por los andadores y la gente les aventaban, de hecho, yo llegué a participar ocasionalmente, lo que pudiera a los granaderos desde las ventanas. Aventábamos cacerolas, tasas, zapatos y, por supuesto, piedras, pedazos de maceta. La gente estaba muy comprometida emocionalmente, 
sentimentalmente, con los estudiantes, porque además la Vocacional 7 era una escuela muy combativa, que llegó a parar, llegó a hacer barricadas, cosas que no se veía en cualquier escuela de la UNAM o del IPN. (A. Ramos, comunicación personal, 4 de febrero de 2020).

La empatía y la solidaridad detonadas en los vecinos cobraba forma durante los ataques a la Vocacional 7 por parte de granaderos, militares y paramilitares. Así, los estudiantes huían hacia determinados edificios recurriendo a su acervo de conocimientos espaciales, donde - hay que subrayar- la cercanía social era clave. Departamentos y negocios de los edificios Chamizal y Chihuahua, ejemplificando, fueron lugares de resguardo ante las agresiones infringidas antes del 2 de octubre.

En tercera instancia, el apoyo de habitantes de otros barrios y colonias cercanos a la Vocacional 7 fue otro eslabón de las redes solidarias de corte espacial; entre ellos se encontraba Tepito, Peralvillo, Santa Julia y Guerrero. Varios estudiantes de la Vocacional residían en estas colonias de raigambre popular, lugares en los que los alumnos sostenían lazos de parentesco y amistad. En este sentido, resulta relevante resaltar la solidaridad proveniente de jóvenes que pese a no ser estudiantes - algunos de ellos integrantes de pandillas - apoyaban la movilización participando no sólo en las refriegas contra los granaderos, sino también en otras prácticas importantes:

Iban a las brigadas, apoyaban a la limpieza, porque se mantenía todo muy limpio, todo el edificio. Hacían mantas, se quedaban a las guardias. Apoyaban haciendo la comida, operando los mimeógrafos. Tenían muchas actividades y muchos dormían ahí. Ahí se encontraban no sólo estudiantes de las Casas de Estudiantes, que se fueron propiamente a vivir a la Vocacional 7, a pasar todas las noches y todos los días en la Vocacional, sino también mucha gente de por aquí, chavillos que iban a la Vocacional y ahí se quedaban. (G. Guzmán, comunicación personal, 3 de abril de 2019).

Finalmente, otro ingrediente fundamental de las redes solidarias de corte espacial se refiere a las alianzas políticas tejidas entre las escuelas:

Se creó una gran solidaridad y alianza entre la Vocacional 7 y las preparatorias y el barrio universitario; era una gran argamasa, de tal manera que pues yo creo que en varias ocasiones el ejército acordonaba el Centro Histórico y llegaban los chamacos de la Vocacional 7 para romper el cerco, para apoyar a los compañeros de las preparatorias, y viceversa. Había mucho apoyo, mucho respaldo de los chamacos de las preparatorias. Había cierta cercanía geográfica, es lo que es ahora el Eje Central, estaban cerca, había formas de movilizarse, de desplazarse. (J. Valverde, comunicación personal, 7 de mayo de 2019).

Resulta necesario enfatizar que no todas las expresiones de solidaridad al movimiento estudiantil se fincaban en la cercanía espacial. Empero, las redes solidarias de corte espacial jugaron un papel relevante en la construcción y mantenimiento de la acción colectiva en la Vocacional 7.

Como se señaló, durante el 68 hubo una reconfiguración funcional de varios espacios de la Vocacional como resultado de la (re) apropiación material, política y simbólica efectuada por miembros del 
movimiento social. Con base en Harvey (2015) - quien, como se estableció, discierne entre el espacio absoluto, el relativo y el relacional- ¿qué tipo de espacio fue la Vocacional 7 ? ¿Es posible caracterizarlo a partir de estas tres nociones? Para responder estas interrogantes, resulta pertinente considerar que:

El espacio no es ni absoluto, ni relativo ni relacional en sí mismo, pero puede llegar a ser una o las tres cosas simultáneamente dependiendo de las circunstancias. El problema de la conceptualización adecuada del espacio se resuelve a través de la actividad humana respecto a él. Dicho de otro modo, no existen respuestas filosóficas a las preguntas filosóficas que surgen de la naturaleza del espacio: las respuestas están en la actividad humana. La pregunta ¿qué es el espacio? Da paso a la pregunta ¿cómo es que diferentes actividades humanas crean y hacen uso de diferentes conceptualizaciones del espacio? (p. 164).

De este modo, la Vocacional 7 fue un espacio absoluto - medible y cuantificable - a la vez que fue relativo - sujeto a modificaciones; amén de ser un lugar que dinamizaba movilidad y flujos de individuos, bienes y servicios a su alrededor, sobre todo porque estaba inserta en un proyecto urbanístico de gran calado- y también fue relacional —en virtud del conjunto de relaciones sociales y políticas entabladas antes y durante el movimiento del 68-. En síntesis, esta escuela fue un espacio tridimensional. Así, es necesario destacar que los espacios cobran pertinencia analítica para las ciencias sociales, y adquieren vida, no por sí mismos, sino por la dinámica social, económica, cultural y política generada en él y con él; es la acción social, en sus diversas modalidades y escalas, la clave para definir al espacio; materialidad, funcionalidad, intencionalidad, relaciones, prácticas sociales y sentido se interconectan en su configuración.

\section{El cierre de la Vocacional 7: clausura de un modelo educativo y embate sociopolítico}

El 23 de septiembre de 1968 el ejército tomó las instalaciones de la Vocacional 7 para nunca más devolverlas al IPN. Esta medida estaba inscrita en todo un operativo estatal en el que mediante la toma de las Vocacionales 2 y 5, de la Unidad Profesional Zacatenco y del Casco de Santo Tomás, se buscaba desarticular la movilización estudiantil desde su núcleo organizativo: las escuelas. Pese a ello, los jóvenes politécnicos defendieron dichos recintos. La ocupación de la Vocacional 7 significó para varios estudiantes, un punto de inflexión: "Ya no teníamos la sede, ni la identidad, ni el lugar donde habíamos llevado a cabo la lucha" (M. Espinal, comunicación personal, 26 de mayo de 2019). El espacio como corazón aglutinador donde los estudiantes organizaban diversos repertorios, deliberaban y decidían; matriz en la que se erguía la vida cotidiana en función de la huelga; referente identitario previo al 68 y durante el mismo, e imán sociopolítico y espacial para otras escuelas, fue tomado ilustrando que la movilización colectiva se hace no sólo sobre el espacio, sino con él. Así, la espacialidad no sólo es un recurso de movilización social, sino también puede ser un recurso de desmovilización.

Tras el cierre de la Vocacional 7 en Tlatelolco, los alumnos fueron enviados a otras sedes con la finalidad de que concluyesen sus estudios: 
Yo creo que pensaban que, cambiándonos de escuela, de norte a sur y de este a oeste, iban a terminar con el movimiento y no podían, nos mandaban de Tlatelolco a Zacatenco. Nos mandaron luego a Cuatro Caminos, al Toreo, a otra escuela, que iba a ser para la Vocacional 2, y era lo mismo, trataron de imponer una nueva dirección estudiantil y pues los chavos la rechazaban. De ahí dijeron ya van ustedes a tener edificio propio en Iztapalapa. De alguna manera también nos iban debilitando. Cuando llegamos a Iztapalapa el edificio estaba rodeado de granaderos (F. Posadas, comunicación personal, 19 de junio de 2019).

Finalmente, la Vocacional 7 fue reubicada en Iztapalapa, localización actual. El cambio de sede también representó una transformación curricular, donde el proyecto educativo multidisciplinar que caracterizó a esta escuela fue cancelado definitivamente por el IPN. De forma semejante, las prevocacionales del IPN, también participantes en el 68 fueron canceladas a raíz de este conflicto.

Después del 2 de octubre de 1968, y tras la reanudación de clases, los comités de huelga se convirtieron en comités de lucha. Los seis puntos del pliego petitorio pasaron a un segundo plano ante las demandas de liberar a los presos políticos y la devolución del edificio de la Vocacional 7 en Tlatelolco. Una vez reiniciadas las clases, el gobierno y las autoridades politécnicas desplegaron otro repertorio represivo: la expulsión de líderes estudiantiles de diversas escuelas con el propósito de aleccionar, y particularmente evitar, la organización autónoma. Representantes de la Vocacional 7 en el $\mathrm{CNH}$ - como Jesús Vázquez y Florencio Posadas - fueron expulsados. La necesidad de recuperar la vida escolar, el cambio de sede, así como el que algunos activistas ingresaran a otras instituciones con el objetivo de cursar una licenciatura, quebrantó la participación sociopolítica en esta Vocacional. Empero, aquel saber organizativo y de resistencia labrado antes del 68, y durante el mismo, fue llevado a otros espacios educativos dentro y fuera del IPN, y a otras luchas durante la década de los setenta.

En 1970 las instalaciones de la Vocacional 7 fueron reestructuradas para convertirse en el Hospital General de Zona Número Uno del Instituto Mexicano del Seguro Social (IMSS). En 2013, fue demolido el edificio. Lo único que queda de la Vocacional es el auditorio - ahora Teatro Isabela Corona - el resto es un terreno baldío (Ver Fotografía 1). 


\section{Fotografía 1}

Antiguo auditorio de la Vocacional 7, hoy Teatro Isabela Corona.

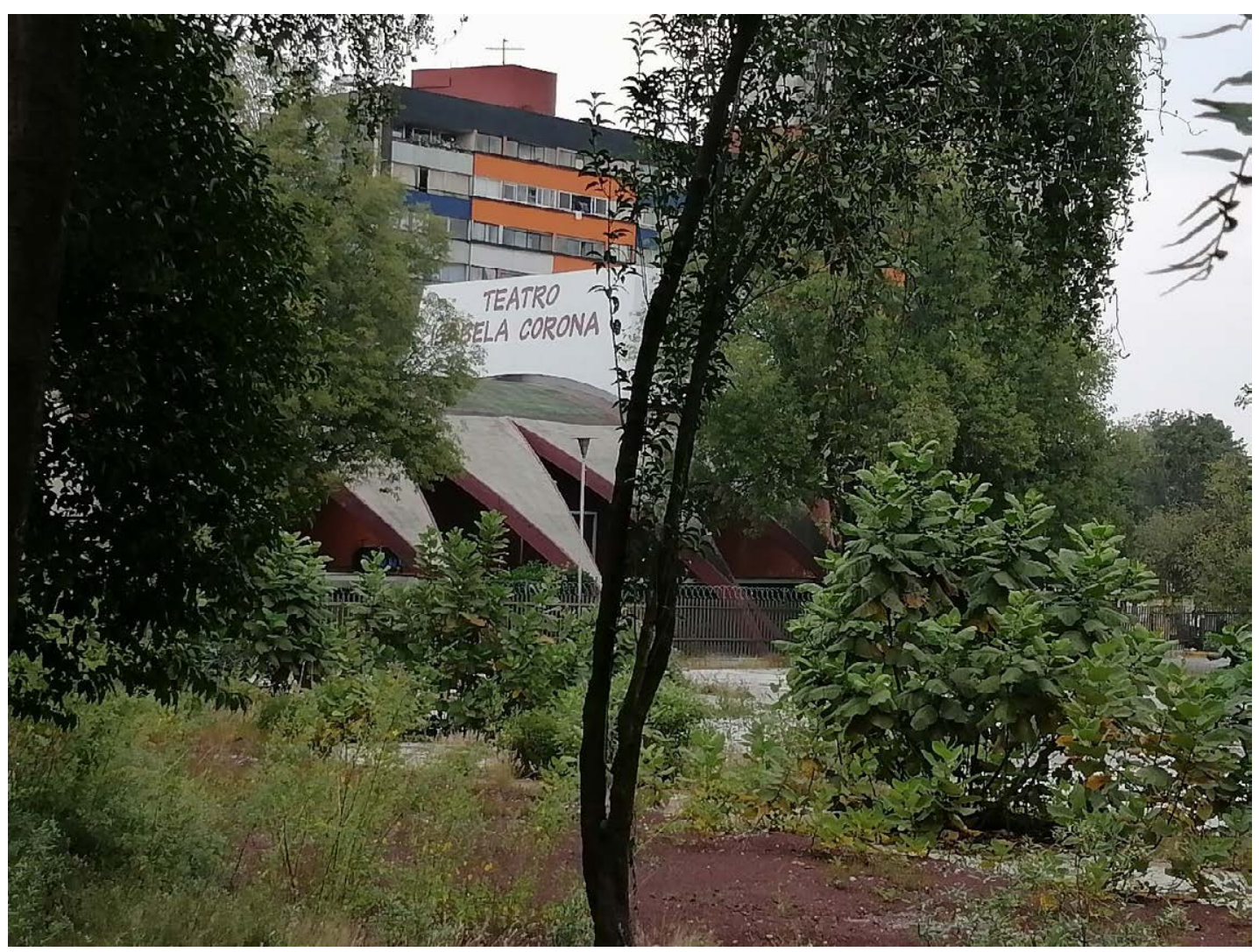

Fuente: Archivo personal, 2020.

La transformación del uso social del espacio - y por tanto los cambios de esta escuela como espacio concebido, percibido y vivido- y su posterior derrumbamiento, ha detonado un sentimiento de agravio en los exestudiantes:

Cuando la cierran, cuando la derrumban, cuando la convierten en hospital, vimos que era parte de una gran maniobra, de una gran hipocresía, de que la gente no se enterara qué había sido, que no fuera un testimonio, que no se convirtiera en un museo, que no se convirtiera en un centro que dijera: "aquí fue la represión, aquí hubo muertos, aquí hubo fulano y zutano, aquí estuvieron". Entonces le cambian la fisonomía. Primero; le cambian de función, le cambian la identidad. Y luego la desaparecen. Entonces a nosotros nos parecía una agresión, pero además otra cosa: ¡la sociedad política ya no defendió a la Vocacional 7! Porque era un patrimonio, no sólo de los estudiantes, era un patrimonio arquitectónico, histórico del IPN. Muchos dirigentes políticos, que se formaron en el 68, no hicieron nada. Nosotros por ahí - ya dispersos, desorganizados, ya viejos, por decirlo así- no tuvimos el tino, la iniciativa para recuperar a la Vocacional 7. (M. Espinal, comunicación personal, 26 de marzo de 2019). 
A la topofilia existente antes del 68, se le sumó otro componente: la participación en dicho movimiento. A más de cincuenta años, la memoria — definida como representación del pasado desde el presenteconstituye otro ingrediente de la topofilia y de la identidad:

Todos los sobrevivientes de la Vocacional 7 tenemos esa huella que nos identifica, el haber participado en el movimiento o incluso ser parte de esa generación. No todos participamos igual: unos más, otros menos, otros no, pero todos somos de la misma generación y es como ser compañero de pupitre, eso nunca se olvida. Cada vez que veo o hablo o tengo conocimiento de algún compañero, me da mucho gusto, todo esto forma parte de nuestra identidad. (F. Posadas, comunicación personal, 19 de junio de 2019).

\section{Conclusión}

Como se expuso, el espacio y el tiempo son dimensiones que estructuran la vida social en sus diversas escalas. Ambos son construcciones sociales y culturales que son producto de la dinámica societal a la vez que inciden en ella. Existe un consenso en el pensamiento filosófico, sociológico y geográfico sobre el vínculo indisociable entre tiempo y espacialidad, a fin de cuentas, el mundo social se configura y reproduce en el aquí y en el ahora, para posteriormente ser materia del pasado, o sea, memoria, que será reinterpretada a partir de las necesidades del presente y las expectativas del futuro y donde, como bien apuntó Halbwachs (2011) el espacio y el tiempo - junto con el lenguaje- constituyen los marcos sociales de la memoria. El maridaje existente entre lo temporal y lo espacial se sintetiza en la expresión de Schlögel (2007): “en el espacio leemos el tiempo", afirmación que permite inferir cómo la historicidad de grupos sociales - formas de relacionalidad política y social; prácticas; acciones; conflictos; memoria, instituciones, utopías y subjetividades - se inscriben en el espacio a manera de marcas territoriales. No obstante, espacio y tiempo pueden ser estudiados y problematizados de forma separada con fines meramente analíticos, tal como se realizó en este artículo. A diferencia del tiempo, el espacio fue obviado en el análisis sociológico al ser contemplado como un mero escenario de la acción social y política y no como un factor vertebral que posibilita y a la vez constriñe el quehacer humano en sus múltiples formas.

Los movimientos sociales son una forma de participación sociopolítica, una construcción social que encierra racionalidad - valores, creencias, emociones, razones- organización, sentido e identidad. El movimiento estudiantil de 1968 fue un sujeto que desafió frontalmente al autoritarismo distintivo del sistema político mexicano. La Vocacional 7 fue uno de los varios eslabones del entramado de alianzas políticas entre las diversas escuelas y universidades de todo el país que erigieron a este actor. Esta escuela, que para entonces era un incipiente proyecto educativo del IPN, se tornó en una de las más participativas. Su ubicación geográfica, capacidad organizativa y para recabar recursos económicos, así como el sentimiento de pertenencia de los estudiantes, representaron recursos espaciales, políticos, materiales y simbólicos de gran valía en la construcción y mantenimiento de la movilización. Este despliegue sociopolitico, empero, no surgió de la nada. Como suele suceder con los sujetos colectivos, los estudiantes de la Vocacional 7 contaban con lo que he definido como un saber organizativo y de resistencia que facilitó la constitución del movimiento al interior de esta escuela en 1968. 
Numerosos analistas han sostenido que la identidad colectiva es un componente definitorio de los movimientos sociales. En la Vocacional 7, dicha identidad fue erigida antes del conflicto estudiantil para posteriormente ser reconfigurada durante el mismo-. Los lazos sociales, la vida académica y política, las prácticas culturales y deportivas fueron labrando un proceso identitario en el seno de la vida cotidiana, misma que se estructura espaciotemporalmente. La identidad debe ser comprendida en una doble dimensión: a partir del campo de relaciones y prácticas sociales; y de la interacción con y en el espacio. Así, lugares como el auditorio, las canchas deportivas, las aulas, la cafetería, los laboratorios, la biblioteca, están imbuidos de significados por los exestudiantes en virtud de la dinámica de apropiación material y simbólica y de la relacionalidad social. A manera de hipótesis, he planteado cómo la identidad colectiva es un ingrediente de la topofilia, misma que puede ser vista como un indicio identitario. En consecuencia, la Vocacional 7 como espacio material, social, político y simbólico —o sea como espacio de vida - es un ingrediente de la identidad.

Como toda modalidad de acción social, la colectiva está espacializada y temporalizada, es decir, se gesta y desarrolla en lugares determinados y en tiempos específicos, además de ser fruto de la historicidad y abonar a la construcción de esta. Pensar al espacio como mero escenario de la acción sociopolítica constituye una limitante analítica. Los movimientos sociales no sólo se erigen y desarrollan en espacios concretos, en ocasiones también eclosionan en defensa de estos - como los movimientos urbanos o los ambientales - casos donde explícitamente lo espacial está en los objetivos de la lucha. Si como asevera Lussault (2015), se actúa con el espacio, entonces éste es un recurso material, político y simbólico para la movilización. Repertorios de confrontación, discursos e identidades no sólo se inscriben en el espacio público, sino también contribuyen a su edificación.

En el caso de la movilización de la Vocacional 7, lo espacial jugó un rol importante en su construcción y conservación; en las expresiones de apoyo - a las que he denominado redes solidarias de corte espacial- y en su propio desmantelamiento. Los jóvenes desplegaron estrategias territoriales, al igual que sus adversarios, donde la toma definitiva de la escuela fue un revés sociopolítico contundente.

Desde un ejercicio memorístico, para algunos exestudiantes la participación en el 68 es un referente identitario y otro componente de la topofilia. El cambio de sede de la Vocacional 7, su transformación en hospital y postrera demolición, han sido una fuente de agravio para varios exalumnos, mismos que están demandando al IPN y al gobierno federal su reconstrucción, tal como lo hizo Mario Pani, con la finalidad de crear un espacio de memoria sobre el IPN y el 68. Subyacente a esta exigencia, está el reconocimiento implícito de la estrecha relación existente entre espacio, identidad y memoria colectiva, vínculo que representa otro desafío analítico necesario de explorar.

\section{Referencias}

Álvarez Garín, R. (2002). La estela de Tlatelolco. Itaca.

Berger, P. y Luckmann, T. (2001). La construcción social de la realidad. Amorrortu.

Cantú, R. (2001). Tlatelolco. La autoadministración en unidades habitacionales. Gestión urbana y planificación. Plaza y Valdés.

Cedeño, L. (2003). Vocacional 7: esplendor y recuperación. IPN. 
Excélsior. (22 de septiembre de 1968). Violentas refriegas en Tlatelolco. http://www.excelsior. com.mx/nacional/tlatelolco-convertido-en-epicentro-del-conflicto-1266753

Halbwachs, M. (2011). La memoria colectiva. Miño y Dávila.

Harvey, D. (2015). El cosmopolitismo y las geografías de la libertad. Akal.

Heidegger, M. (1994). Conferencias y artículos. Ediciones del Serbal.

Lefebvre, H. (2013) La producción del espacio. Capitán Swift.

Lindón, A. (2012). La concurrencia de lo espacial y lo social. En E. De la Garza y G. Leyva (Coords). Tratado de Metodología de las ciencias sociales: perspectivas actuales. (pp. 585-616). Fondo de Cultura Económica.

Lindón, A. (2014). El habitar la ciudad, las redes topológicas del urbanita y la figura del transeúnte. En D. Sánchez y L. A. Domínguez (Coords.) Identidad y espacio urbano, (pp. 55-77). Gedisa.

Lussault, M. (2005). El hombre espacial. La construcción social del espacio humano. Amorrortu.

Revilla Blanco, M. (1994). El concepto de movimiento social: acción, identidad y sentido. Última década. (005), 1-18.

Schlögel, K. (2007). En el espacio leemos el tiempo. Sobre Historia de la civilización y Geopolítica. Siruela.

Schutz, A. y Luckmann, T. (2003). Las estructuras del mundo de la vida. Amorrortu.

Tamayo, S. (2015). Espacios y repertorios de la protesta. UAM.

Tamayo, S. y Wildner, K. (2005). Identidades urbanas. UAM.

Touraine, A. (1995). Producción de la sociedad. UNAM

Tuan, Y. F. (2007). Topofilia. Melusina.

Valencia, G. (2007). Entre Cronos y Kairós. Las formas del tiempo sociohistórico. UNAM.

Valverde, J. (2018). 1968. Si avanzó sígueme, si me detengo empújame. Orfila. 

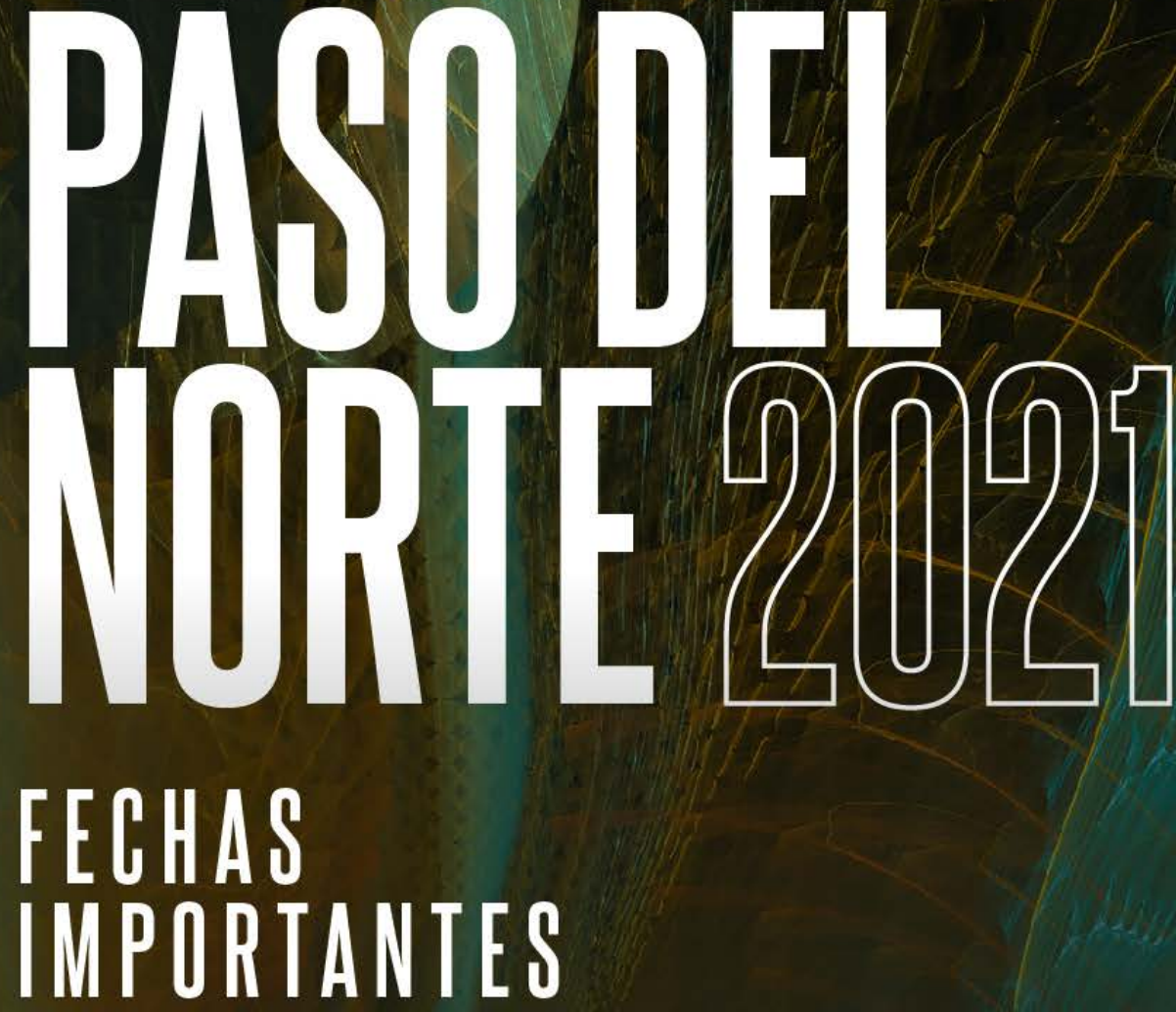

Recepción de trabajo

Del 15 de febrero al 7 de junio

Publicación de propuestas aceptadas 30 de julio

\begin{tabular}{ll}
\hline Fecha límite envío ponencias in extenso & $\mathbf{3 0}$ de septiembre \\
\hline Fecha límite de inscripción para ponentes & $\mathbf{8}$ de octubre \\
\hline Publicación del programa del Congreso & $\mathbf{2 2}$ de octubre \\
\hline Realización del Congreso & del $\mathbf{8}$ al $\mathbf{1 1}$ de noviembre \\
\hline Fecha límite para trámite de constancias & $\mathbf{3 0}$ de noviembre
\end{tabular}

Fecha límite para trámite de constancias

30 de noviembre

Registro de trabajos:

http://info.uacj.mx/congresocs2021 